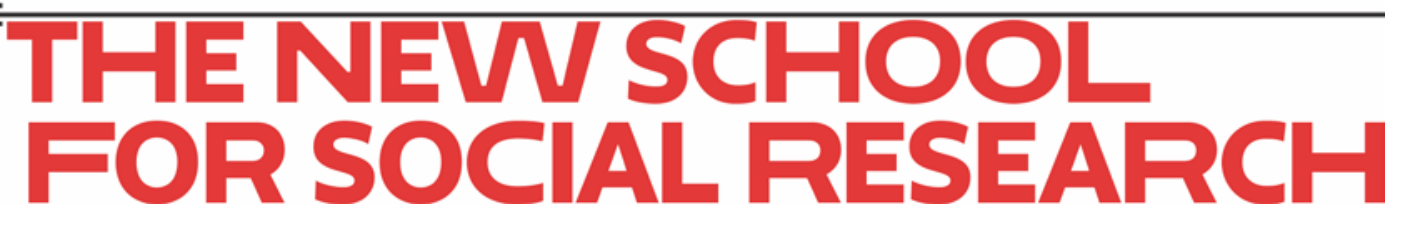

Robert A. Blecker and Mark Setterfield

\title{
On Multi-Sector and Multi-Technique Models, Production Functions and Goodwin Cycles: A Reply to Libman
}

September 2020

Working Paper 11/2020

Department of Economics

The New School for Social Research 


\title{
On Multi-Sector and Multi-Technique Models, Production Functions and Goodwin Cycles: A Reply to Libman
}

\author{
Robert A. Blecker and Mark Setterfield*
}

August 21, 2020

\begin{abstract}
Emiliano Libman's constructive comments on our recent book, Heterodox Macroeconomics: Models of Demand, Distribution and Growth (HM), raise three main points of contention: the suitability of single-sector/single-technique (as opposed to multisector/multi-technique) models; the appropriate choice of production function; and the distinction between limit cycles and closed orbits as representations of Goodwinian dynamics. In this reply, we respond to Libman's critique in a manner that is designed to develop his arguments into a useful addendum to our book. In so doing, we hope that this exchange will engage interested students and other readers in issues and avenues of inquiry that lie beyond some of the first-pass simplifications in $H M$.
\end{abstract}

JEL codes: E11, E12, O33, O41, B51, D24

Keywords: Choice of technique, production functions, Goodwin cycles, multi-sectoral models, technological change, factor substitution

\section{Introduction}

We are grateful to Emiliano Libman for his comments (Libman, 2020) on our recent book Heterodox Macroeconomics: Models of Demand, Distribution and Growth (Blecker and Setterfield, 2019) - hereafter HM. His comments are thoughtful, carefully developed and generous - and are clearly based on a close reading of our book. We certainly accept his endorsement

*Blecker: American University; blecker@american.edu. Setterfield: New School for Social Research; mark.setterfield@newschool.edu 
where he writes that ' $H M$ is a must read [not only for] anyone curious about non-mainstream economics, but also for those who have been taking the alternative approaches more seriously and systematically' (Libman, 2020, p. 1; italics added).

Libman's comments identify three main points of contention: single-sector or singletechnique versus multi-sector or multi-technique models; continuous versus fixed-coefficient production functions; and limit cycles versus closed orbits as representations of Goodwin models. While we will respond in detail below, we would note here that all of Libman's critical comments are focused on chapter 2 of $H M$, which covers classical-Marxian models. To put this chapter in context, it is important to explain how it fits into the overall objectives of our book. In writing $H M$, our objective was two-fold. First, we put primary emphasis on post-Keynesian models of demand-led growth, which occupy eight of the book's ten chapters (chapter 2 is the main exception, as it covers strictly supply-driven models). Second, we sought to make the presentation accessible to first-year graduate students or, indeed, advanced undergraduates in economics. For both of these reasons, the discussion of classical-Marxian models in chapter 2 was necessarily short and simplified, intended only to give the reader a quick overview of material that we know is covered more fully in other sources (for example, Kurz and Salvadori, 1995, Foley et al., 2019).

Libman acknowledges that our approach is an appropriate starting point for discussions of the three issues he raises. As such, we will not seek to defend our work on the ground that it is intended as a point of departure (although that is especially true for chapter 2). Instead, this reply largely seeks to embrace and embellish, rather than deny or reject, Libman's comments. In so doing, we hope that this exchange will serve as a useful addendum to our book as well as a response to his critique, directing interested students and other readers toward issues and avenues of inquiry that lie beyond some of the first-pass simplifications in $H M$. 


\section{Innovation, choice of technique and multi-sector mod- els}

Libman (2020) admonishes us for the simplifying device we employed throughout the first several chapters of $H M$ of assuming a one-sector economy characterized by a single, linear 'dominant technique' of production, although he also notes that 'this is a very standard procedure and a very reasonable way to approach the task at hand'. As Libman correctly notes, the assumption of a single good makes our wage-profit frontiers linear, thus avoiding the nonlinearities that have been emphasized in many theoretical discussions - especially the Cambridge capital controversies of the 1960s ${ }^{1}$ In fact, the Cambridge capital controversy is discussed in a lengthy endnote in $H M$, while the fact that wage-profit (unit cost) curves are nonlinear in neoclassical models with continuous factor substitution is discussed elsewhere (see Blecker and Setterfield, 2019, notes 4, 8, pp. 99-100). Our book refers the reader to sources (Harcourt, 1972, Pasinetti, 1977; Harris, 1978) that elucidate the capital controversies in great detail, which (as we think Libman would concede) would be beyond the scope of $H M$. Nevertheless, we should have noted that the inverse wage-profit relationship is strictly downward-sloping under much more general assumptions about the technology and number of goods - something that we usually point out in our class lectures, but inadvertently neglected to say in the book.

Libman (2020) also criticizes us for not distinguishing more carefully between technical progress and the choice of technique. Of course, in principle the development of new technologies (innovation) is distinct from the choice among a given set of existing techniques, or in microtheoretic terms, a move along a production function to a different combination of inputs is different from a shift in the production function itself - where the latter im-

\footnotetext{
${ }^{1}$ As Libman also notes, some heterodox economists argue that, as a matter of empirical fact, the wageprofit frontier is essentially linear (see, for example, Shaikh, 2012, 2016).
} 
plies an alteration in the entire mapping of inputs into outputs. In $H M$, we discussed the choice of technique only briefly, and in the context of capitalist firms choosing between a single previously existing technique and one new or innovative technique, and hence we did not emphasize that distinction. This analysis was deliberately simplified for pedagogical purposes and, once again, the need to squeeze a lot of material into chapter 2. However, contrary to what Libman states, we do not think there is any inconsistency in assuming both: (a) that there is one technique (like $\alpha$ in his Figure 1) available ex ante, and then a choice of technique problem arises when a new technique (his $\beta$ ) is introduced as a result of an innovation; and (b) our assumption, in later parts of the book, of what Libman calls a 'dominant technique' being in use. We did not mean to deny the possibility that there could have been a prior choice of technique before the innovation, but merely assumed (as a simplifying device) that the prior technique in use was a settled matter when the innovation occurred - and, similarly, if the new technique is adopted, the older one eventually becomes irrelevant (as discussed further below).

Libman also points out, quite correctly, that when more than one technique is available, the effective wage-profit relation becomes the outer envelope of the intersecting curves (lines, if they are linear) for the various potentially viable existing techniques. The points on the interior portions of relations like $\alpha$ and $\beta$ in his Figure 1 are never observed in equilibrium.2 Thus, he argues that our use of a unique linear relationship in most of our discussion (except where we are explicitly analysing technical change) must reflect the implicit assumption that a single 'dominant technique' prevails at any point in time.

On these points, we do plead guilty, but we would defend our approach. The idea that

\footnotetext{
${ }^{2}$ One exception could be if one of the techniques is an older one that was adopted under an earlier configuration of prices and available choices, and the fixed costs of switching to the new technique would outweigh the savings in variable costs for some firms. Technological lock-in (David, 1985, 2000), resulting from interconnectedness between components of the production process, is another problem that can frustrate switching between techniques of production. Finally, information problems or financial constraints might prevent some firms from adopting the theoretically profit-maximizing or cost-minimizing technique.
} 
firms have to innovate in order to find alternative techniques to choose among is not an unusual idea, either in heterodox economics or in mainstream analysis of technological change. Among post-Keynesian theorists, Robinson (1956) famously introduced the metaphor of a 'book of blueprints' to describe the vast array of possible techniques described by a standard neoclassical production function (isoquant). However, her point was a critical one: she insisted that firms cannot generally find ready-made blueprints for new techniques that they might like to switch to, but rather need to invent them or modify existing ones - so that a shift to a new technique normally requires a costly act of innovation and/or modification. As she later wrote, 'There are no ready-blue-printed techniques to choose from. When the technique to be installed is designed to give a higher output per man [sic] than that formerly in use, it must be a recent innovation or an adaption from one already known in the broad, though not in detail' (Robinson, 1975, pp. 38-39).

This argument was later pursued by economic historian Nathan Rosenberg, who cast significant doubt on the very idea that 'factor substitution' (in the sense of choosing among a wide-ranging set of alternative, existing techniques) was possible in the absence of a significant and costly innovative effort:

If, in response to a change in factor prices, a firm has to commit resources to establishing new optimal input mixes, should not the activity leading to the new knowledge be described as technological change and not factor substitution? ... Once a substantial research expenditure is required for what is called "factor substitution," what is left of the economic basis for the distinction between technological change and factor substitution? (Rosenberg, 1976, p. 64)

From this perspective, perhaps we were not wrong to treat the choice of technique within the context of the adoption of a technological innovation, since the latter is generally necessary to facilitate the former. 
Rosenberg (1976) also makes another important point: once new techniques are adopted, the old ones eventually fade away from the practically feasible technology set; they are no longer available to firms as relevant alternatives that could be chosen. For example, the technology of how to smelt iron in a fireplace or how to manage a transportation system using horses and buggies has been lost; they are not in the pertinent choice set facing modern firms ${ }^{3}$ As Rosenberg wrote,

Since - to introduce a primary assumption of my argument - the production of knowledge is itself usually a costly activity, why should technological alternatives representing factor combinations far from those justified by present prices be known? Why should a society, where the price of capital is low relative to that of labor, have available detailed information about labor-intensive techniques of production? ... profit-oriented business firms do not ordinarily commit resources to the generation of knowledge which has no prospective relevance whatever to their productive activities. (Rosenberg, 1976, p. 63)

Thus, even the memory of older techniques, which may have been viable alternatives in the past (or could still be viable but only at very different wage-price combinations), is not maintained by current firms..$^{4}$ Indeed, Foley et al. (2019, p. 147) formalize this in their 'fossil production function', in which older, more labour-intensive techniques are seen as 'the fossil record of past technology'. For all these reasons, we think that the assumption of a single, dominant technique at any point in time is actually a reasonable approximation for a book focused on macroeconomic models of growth and distribution. It is not surprising to find

\footnotetext{
${ }^{3}$ Of course, we do not deny that some older techniques may be preserved as historical relics for various reasons, including religious requirements, ceremonial usages, tourist displays and artisanal production, but they are no longer practically available choices for normal industrial production.

${ }^{4}$ Since one of the present authors (Blecker) was a student of Rosenberg's at Stanford University in the early 1980s, he can confirm that Rosenberg also said (in his lectures) that firms do not commit resources to maintaining knowledge about obsolete techniques or ones that are no longer relevant under current cost conditions.
} 
that this assumption has been used extensively in a variety of other heterodox texts (for example, Marglin, 1984; Dutt, 1990; Foley et al., 2019).

These reservations aside, there is no doubt that the distinction between single- and multisector analysis is worthy of further discussion. For example, the capitalist growth record clearly demonstrates the importance of 'growth as transformation' or, in other words, the fact that capitalist growth involves ongoing structural change. This is reflected in continual decline in the importance of the agricultural sector, the rise and subsequent decline of manufacturing, and the relentless rise of the service sector, the latter trends having resulted in the contemporary deindustrialization and tertiarization of advanced capitalist economies as well as many middle-income countries. Structural change has long been acknowledged by Kaldorians (Cornwall, 1977) - so much so that it is now given equal footing, along with the principle of effective demand, as one of the key 'drivers' of growth in some quarters of the Kaldorian literature (see, for example, Thirlwall, 2013). It is equally prominent in contributions such as Pasinetti (1981).

Mention (if not full and proper discussion) of structural change can certainly be found in the chapters of $H M$ that deal with Kaldorian growth theory - including the prominence of the manufacturing sector in explanations of technical change that draw on the Verdoorn law, and the multi-sector model of balance-of-payments-constrained growth due to Araujo and Lima (2007). The theme certainly merits closer attention, however - not least because structural change can make a demonstrable contribution to the processes responsible for generating increasing income inequality, and is therefore of obvious significance in modelling frameworks (post-Keynesian and classical-Marxian alike) that take the distribution-growth nexus seriously.

To see this, note that in a one-sector economy (of the sort that, per Libman, populates $H M)$, the wage share of income is easily expressed as: 


$$
\psi=\frac{w L}{Y}=w a
$$

where $\psi$ denotes the wage share of income, $w$ is the real wage, $L$ is the level of employment, $Y$ is the level of real output, and $a$ denotes the labour-output coefficient (the reciprocal of the level of labour productivity). But now consider a two-sector (manufacturing, $M$, and services, $S$ ) economy. In this case:

$$
\psi=\frac{W_{M} L_{M}+W_{S} L_{S}}{P_{M} Y_{M}+P_{S} Y_{S}}
$$

where $W$ and $P$ denote the nominal wage and price level in a sector, respectively. If we choose $P_{S}$ as the numeraire, then we can write:

$$
\psi=\frac{w_{M}^{S} L_{M}+w_{S} L_{S}}{Y^{S}}=w_{M}^{S} \frac{L_{M}}{Y_{M}^{S}} \frac{Y_{M}^{S}}{Y^{S}}+w_{S} \frac{L_{S}}{Y_{S}} \frac{Y_{S}}{Y^{S}}
$$

where $w_{M}^{S}=W_{M} / P_{S}$ and $Y^{S}=Y_{M}^{S}+Y_{S}=\left(P_{M} Y_{M} / P_{S}\right)+Y_{S}$ are (respectively) the real wage in sector $M$ and aggregate real output when $P_{S}$ is used as the price deflator, and $w_{S}$ is the producer real wage in sector $S$. It follows that:

$$
\psi=\alpha w_{M}^{S} a_{M}^{S}+(1-\alpha) w_{S} a_{S}^{S}
$$

where $a_{M}^{S}$ and $a_{S}^{S}$ are the sectoral labour to output ratios specific to the choice of $P_{S}$ as numeraire, and $\alpha=Y_{M}^{S} / Y^{S}$ the share of aggregate real output $Y^{S}$ in sector $M$ (so that $1-\alpha$ is the share of $Y^{S}$ in sector $S$ by construction, there being only two sectors).

On the face of it there is little difference between the expressions in equations (1) and (2), the second being merely a weighted average. The difference seems even more slight if, consistent with the single-sector assumptions employed in $H M$, we assume that in both sectors $M$ and $S$ there is a constant real wage and no (labour-saving) technical change. But 
suppose that, following Cornwall (1977), there exists a 'commodity hierarchy' such that, in a growing economy, shifts demand from sector $M$ to sector $S$ as a result of different income elasticities of demand in these sectors. This means we will observe $\dot{\alpha}<0$. Then $\psi$ will remain constant only in the special case where $w_{M}^{S} a_{M}^{S}=w_{S} a_{S}^{S}$ - that is, when there is effectively only one sector in terms of the structure of the supply side (as reflected in the productivity and remuneration of labour). In short, structural change that alters the sectoral composition of output between sectors that differ with respect to the level of wages and/or the productivity of labour can, in and of itself, create a trend rise or decline in the wage share of income. Clearly, there is much to be learned from studying structural change in a multisector economy that is important for any class of models that takes the distribution-growth nexus seriously.

\section{Continuous versus fixed-coefficient production func- tions}

Libman (2020) argues that our reliance on a Leontief (fixed-coefficients) production function invites continuation of the general neglect in heterodox economics of continuous substitution possibilities and, in so doing, risks overstating the importance of the form of the production function as a source of difference between heterodox and neoclassical macroeconomics. Libman is certainly correct that heterodox and neoclassical economists can and do overlap in their use of these different kinds of production functions. Ros (2013) is a recent example of a structuralist/heterodox text on economic development that makes extensive use of conventional production functions that allow for continuous factor substitution. Mainstream uses of Leontief technologies are too frequent to require citations here. Moreover, Libman is also correct that many economic models can be re-cast using the opposite of the more commonly used form the production function (his example is a Solow growth model with 
fixed coefficients, which we discuss further below).

Nevertheless, we think it is a 'stylized fact' of the contemporary economics profession that mainstream economists primarily use neoclassical production functions, while heterodox economists usually employ Leontief ones, and the reverse usages are the exceptions rather than the rule. Moreover, we think there are good reasons for this correlation of schools of thought with modes of modelling the production process, because the difference between the two specifications is more than a simple choice of mathematical techniques. Rather, different specifications of the production function relate to substantive theoretical disagreements including the question of whether the marginal productivity theory of 'factor prices' is a valid way of explaining the distribution of income.5 Moreover, the two specifications reflect very different 'pre-analytic visions' of the production process (Heilbroner and Milberg, 1996) - with the heterodox vision firmly rooted in an understanding that capitalism, as reflected in the historical record of the past 200 years, is (or should be) the object of analysis of economic inquiry.

As noted in our chapter 1 ,

any theoretical model is an abstraction, and the two extreme cases depicted in Figure 1.1 [in $H M$ ] of only a single technique [Leontief production function] or an infinite array of techniques [neoclassical production function with continuous substitution] are merely theoretical devices. Most heterodox economists, however, believe that a focus on a small number of discrete techniques (with innovation required to develop new ones) is a better first approximation to reality than the assumption of an infinite range of techniques with a given technology. (Blecker and Setterfield, 2019, p. 14.)

\footnotetext{
${ }^{5}$ We note that this same issue motivates much of Libman's concern with single- versus multi-technique analysis, as an outgrowth of the Cambridge capital controversies, discussed in the previous section. In this way, and pace Libman, it is not obvious why heterodox economists concerned with the implications of multitechnique analysis should simultaneously bemoan a neglect of continuous substitution possibilities in the modelling of production.
} 
To explain why, we would again refer to the arguments of Rosenberg (1976, p. 64), who used a pair of isoquant diagrams to contrast his view of technology with the more conventional neoclassical perspective. Panel (b) in Figure 1 shows the neoclassical view, which Rosenberg describes as 'a smooth, continuous curve' (isoquant) offering a wide range of alternative techniques that can be freely chosen - with no costs or innovations required to switch from one to another - based on the prevailing factor prices. In contrast, his own view that 'the known portion of an isoquant typically [is] a relatively small segment' is depicted in panel (a) of Figure 1. Of course, a clever microeconomist could easily represent something like the isoquant exhibited in panel (a) by an appropriate mathematical production function (for example, perhaps one with a very low elasticity of factor substitution). Nevertheless, given the very limited choice of technique available on that small segment, a Leontief production function with an L-shaped isoquant in the vicinity of that short curve is arguably a better first approximation to the reality described by Rosenberg of a very limited range of choice of technique being feasible sans technological change ${ }^{6}$ Why then emphasize the possibility of a choice of techniques that is at best very limited in the absence of technological innovation?

Applying the principle of Occam's razor, the simpler specification of fixed coefficients seems superior to the mathematically feasible but unnecessarily complicated specification of a 'well-behaved' neoclassical production function, especially when the latter brings with it substantial theoretical baggage that may be undesirable or, at best, unnecessary for the task at hand. For example, a standard neoclassical production function implies an inverse relationship between the profit rate and quantity of capital, which according to the Cambridge capital controversy does not generally exist in a multi-commodity system when the total capital stock is aggregated using prices. As Harris (1978, p. 146) states when summarizing

\footnotetext{
${ }^{6}$ Of course, we do not dispute that the short segment of an isoquant that represents the available range of techniques could be located in different portions of $L \times K$ space in different countries or global regions, as the available techniques in any particular economy would be a path-dependent product of the historical trajectory of technological innovation and adoption in that economy.
} 


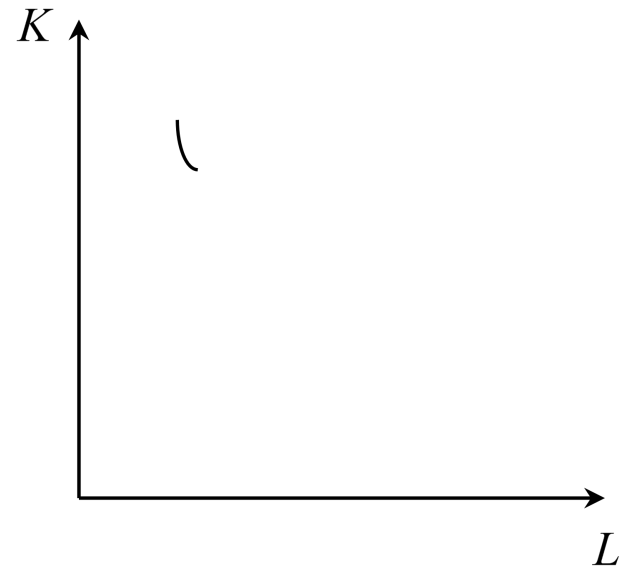

(a) Rosenberg isoquant

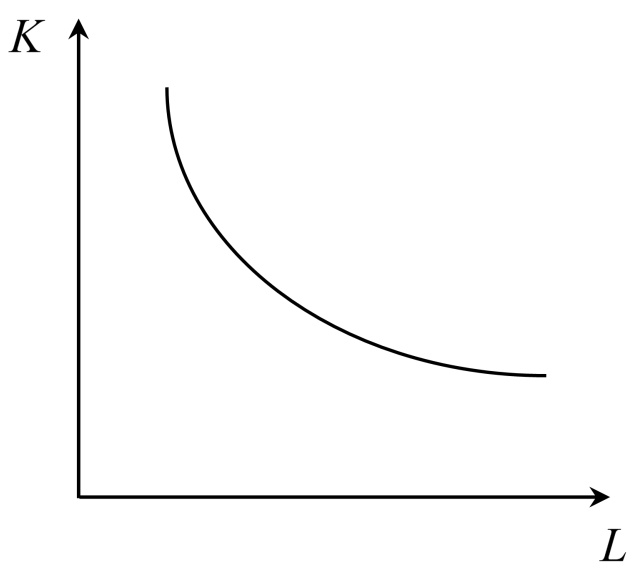

(b) Neoclassical isoquant

Figure 1: Alternative visions of the production function

the outcome of that controversy, 'any presumption that a unique inverse relation exists in general between the quantity of capital, measured in terms of prices, and the rate of profit is untenable'.

The question as to what production function is best suited for heterodox analysis aside, we certainly agree with Libman's more specific arguments that Harrod did not base his analysis on a Leontief production function (nor, indeed, any production function), and that neoclassical growth theory does not depend on the assumption of a continuous production function. With respect to his development of the second of these arguments (to which Libman devotes considerable attention), we would make one small (but important) qualification: while the existence of an equilibrium capital-labour ratio $k^{*}$ in Libman's equation (1), coupled with convergence to this equilibrium value, does ensure $\hat{Y}=n$ (where $\hat{Y}$ is the growth rate of output and $n$ is the growth rate of the labour force), this outcome does not necessarily imply full employment. As we point out in $H M$, in the absence of technical change, $\hat{Y}=n$ ensures a constant rate of employment, but this implies continuous full employment only if 
the economy begins with a level of output consistent with full employment.7

Otherwise, Libman's demonstration - following Solow (1956) - that a neoclassical growth model can 'work' without a continuous production function is beyond reproach. Note, however, that on closer inspection, this same point can be made clear using the technology in $H M$, which covers second-generation (endogenous and semi-endogenous) neoclassical growth theory as well as the Solow model. Hence consider an aggregate production technology of the famous ' $A K$ ' form:

$$
\begin{gathered}
Y=K^{b}(B N)^{1-b} \\
B=\beta \frac{K}{N}
\end{gathered}
$$

where $0<b<1$ and $\beta>0$ are constant technical coefficients, $K$ is the capital stock and $N$ denotes the total labour force 8 Upon substitution, we get:

$$
Y=K^{b}\left[\beta \frac{K}{N} N\right]^{1-b}=A K
$$

where $A=\beta^{1-b}$ is a constant. Using the intensive form of this production function $Q=A k$ (where $Q=Y / N)$ in the basic equation of motion of the Solow model, we get:

$$
\dot{k}=s A k-n k=(s A-n) k
$$

so that equilibrium $(\dot{k}=0)$ in equation (4) is achieved when $s A=n \cdot 9$

\footnotetext{
${ }^{7} \mathrm{~A}$ second minor quibble concerns use of the terms 'first Harrod problem' and 'second Harrod problem'. In $H M$, we use 'first Harrod problem' to denote the improbability of the warranted and natural rates of growth being equal, and 'second Harrod problem' to describe the instability of the warranted rate. Libman reverses our usage.

${ }^{8}$ We equate total employment with the total labour force in this analysis, assuming that the labour market is cleared by a flexible real wage and by normalizing to a value of one the maximum rate of employment associated with this outcome.

${ }^{9}$ We ignore the trivial solution $k=0$ here.
} 
Since $Y=A K$, it follows that:

$$
\begin{gathered}
\hat{Y}=\hat{K} \\
\Rightarrow \hat{Y}=\frac{I}{K}=\frac{s Y}{K}=s A
\end{gathered}
$$

where $I$ denotes investment (the rate of change of the capital stock), $s$ is the proportional saving rate out of income, and we make the neoclassical assumption that saving determines investment. We can therefore write:

$$
\hat{Y}=n
$$

when $\dot{k}=0$ since, as demonstrated above, $s A=n$ when this equilibrium condition is observed. In sum, the model has an equilibrium at which the rate of growth is equal to the natural rate, but the production function is neither Leontief (there is substitutability between capital and labour) nor of the typical (continuous) neoclassical variety (since the capital-output ratio in equation (3) is fixed) ${ }^{10}$

In fact, if we invoke the equilibrium condition $s A=n$, then the equivalent of Figure 4 in Libman (2020, p.8) can be depicted as in Figure 2. This figure depicts the two key components of equation (4) - total investment per worker, $s A k$, and investment per worker necessary to keep the capital-output ratio constant, $n k$ - as two coincident schedules (one lying on top of the other), with intercepts of zero and equal slopes. As Figure 2 shows, the model creates a continuum of equilibria: $s A k=n k \Rightarrow \dot{k}$ is satisfied for any value of $k$. But this non-uniqueness does not deny the existence and stability of an equilibrium rate of growth consistent with $\hat{Y}=n$, which is the focus of attention here. Indeed, the stability of

\footnotetext{
${ }^{10}$ These results reveal the sense in which the AK model is 'Harrod redux'. First, note that $s A=n \Rightarrow \hat{Y}=n$ is a special case, since the parameters $s, A$, and $n$ are all exogenously given and determined independently of one another - which is reminiscent of the first Harrod problem. Meanwhile, the more general case $s A>n$ implies $\hat{Y}>n$, i.e., steady growth in output per worker and hence (under standard assumptions about the constancy of the rates of employment and labour force participation in the long run) output per capita, which the Solow model cannot produce without auxiliary appeal to exogenous technical progress. This is because of the now-constant marginal capital-output ratio, $A$ (violating the law of diminishing returns in the Solow model), as in Harrod.
} 


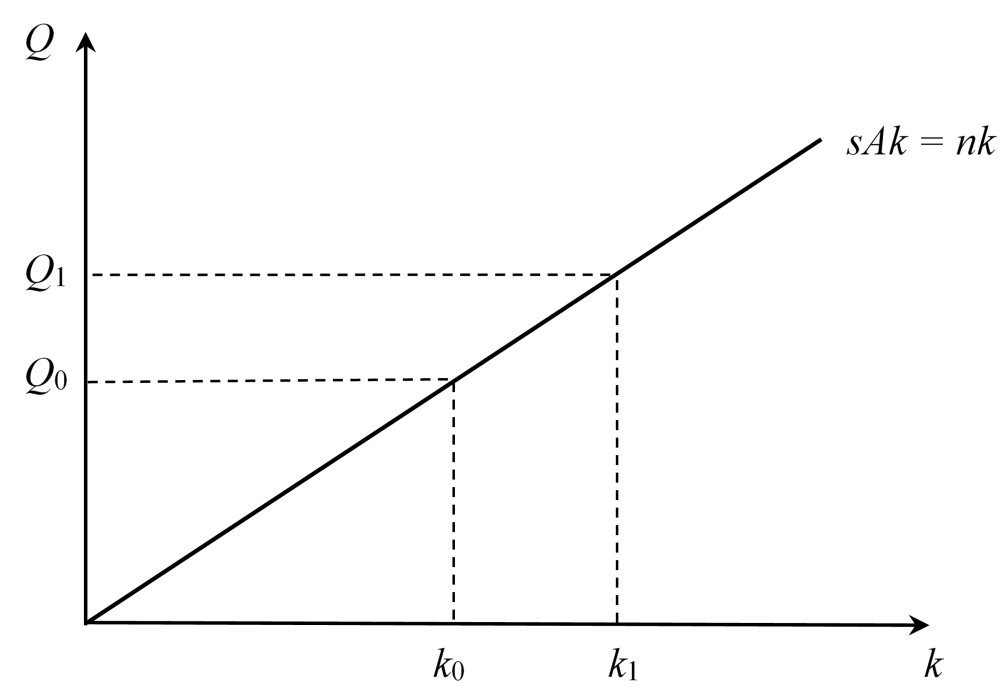

Figure 2: The Solow model with an 'AK' production function

equilibrium in this case means that any arbitrary value of $k$ (such as $k_{0}$ or $k_{1}$ ) in Figure 2 becomes the steady state value of $k$, giving rise to an accompanying steady-state value of output per worker ( $Q_{0}$ or $Q_{1}$, respectively) - and any of these outcomes (being consistent with $s A=n$ ) produces the steady state rate of growth $\hat{Y}=n$. In other words, in addition to reproducing the basic (Harrod-defying) result of the first-generation neoclassical growth model, the model developed here also produces what we describe in chapter 8 of $H M$ as 'weak path dependence' (extreme sensitivity to initial conditions) in levels - specifically, in the values of the capital-labour ratio and output per worker.

\section{Limit cycles versus closed orbits in Goodwin models}

Libman (2020) catches one genuine error in $H M$ : we mistakenly refer to the solution of our Goodwin cycle model in section 2.8 as yielding either 'a "limit cycle" or closed orbit', 
when we should have said that the model we specified in our equations (2.26) to (2.31) only describes a closed orbit (Blecker and Setterfield, 2019, pp. 94-97). Indeed, the source upon which we drew most directly for the math we presented clearly states that 'The solution of this system of differential equations is a closed cycle around the equilibrium point' (Grasselli and Maheshwari, 2017, p. 1766). However, we would note that we correctly drew a closed orbit in our graphical representation of the model in our Figure 2.13, so the damage is limited to this one incorrect statement on p. 97, which appears to have been an editorial oversight on our part. Nostra culpa.

However, we would point out that a simple transformation of our model would, in fact, yield a limit cycle. Foley et al. (2019, pp. 120-125) present a model of a Goodwin cycle that is essentially identical to ours, but with one key difference: it is specified in discrete time with lags, whereas our model is written in continuous time ${ }^{11}$ This difference equation version of what is otherwise the same model does, indeed, generate a limit cycle under reasonable parameter values, as shown in the simulation depicted in the authors' Figure 6.8 (Foley et al. 2019, p. 124) 12

More broadly, a narrow focus on whether a particular model of Goodwin cycles yields closed orbits or limit cycles - while technically a valid distinction - misses the larger picture of the substantive story about business cycles that is told by the Goodwin model, which has inspired a large literature using quite varied mathematical formulations. What characterizes all of these models is that the economy moves through a countercyclical rotation around the equilibrium point in employment rate $\times$ wage share space (or, equivalently, a procyclical

\footnotetext{
${ }^{11}$ Aside from this key difference and the authors' distinctive notation, the only other difference in Foley et al. (2019) is that they include a positive depreciation rate $\delta(0<\delta<1)$ while we assume zero depreciation of capital for simplicity. This does not affect the properties of the models in yielding either a closed orbit or a limit cycle.

${ }^{12}$ Note that because our Goodwin model produces only closed orbits, it displays weak path dependence: its orbit is sensitive to initial conditions. Models that produce limit cycles do not, since they always converge onto the same orbital path. So if some form of historical contingency is considered a virtue, then models that produce closed orbits are arguably superior to those that generate limit cycles.
} 
rotation in employment rate $\times$ profit share space). In the original formulation of Goodwin (1967), the explanation for this direction of rotation is neo-Marxian: rising labour costs during the boom eventually reduce profitability, which then diminishes capital accumulation causing a downturn in economic activity (fall in the employment rate); but once employment has fallen far enough, labour costs eventually fall too, thereby restoring profitability and sparking an upswing in capital accumulation, which then leads the economy into a recovery in which the employment rate again rises (see Blecker and Setterfield, 2019, pp. 94-95).

A qualitatively similar intuitive story lies behind the neo-Goodwinian model of BarbosaFilho and Taylor (2006), except that the employment rate is replaced by the capacity utilization rate as the indicator of economic activity and the model includes a neo-Kaleckian specification of the demand side to drive output. In the neo-Goodwinian model, the rotations are counterclockwise, but do not necessarily follow either closed orbits or limit cycles. Still other models propose alternative mechanisms that also generate rotations in real activity $\times$ factor share space, as discussed extensively in HM. For example, the Skott (1989) model to which Libman (2020, p.11) draws attention - adds explicit goods market dynamics to the labour market adjustments characteristic of the Goodwin model, and generates clockwise rotations in employment $\times$ profit share space but without appeal to the Marxian profit-squeeze mechanism found in Goodwin (1967). Stockhammer and Michell (2016) furnish a model that generates Goodwinesque counter-clockwise rotations in real output $\times$ wage share space, but these arise from real-financial interactions; distributional dynamics are a strictly residual component of their model, playing no causal role in generating the cyclical fluctuations it produces.

This discussion makes clear that it is the rotation (in real activity $\times$ factor share space) that is the truly important feature of Goodwinian dynamics - or what Flaschel et al. (2020, chap. 1) call the Goodwin pattern in the data. Numerous models are capable of producing this rotation, while the precise analytical manners in which they do so (closed orbits, limit 
cycles, or even dynamics that converge towards or diverge from fixed points) are all considered broadly congruent with the Goodwin pattern. This is not altogether surprising because, as is well known, the Goodwin pattern itself (as an empirical entity) is difficult to characterize precisely and its properties do not remain fixed over time. For example, the focus or centre of the pattern shifts between different historical epochs (Barbosa-Filho and Taylor, 2006, Zipperer and Skott, 2011; Kiefer and Rada, 2015; Flaschel et al., 2020) and there are even times when the pattern itself appears to break down (Nikiforos, 2017; Flaschel et al., 2020). The period of the Goodwin pattern is also imprecise, although there seems to be a broad consensus that it is a high-frequency phenomenon which is characteristic of (relatively) short cycles in the economy but not evident in the longer term (Flaschel and Groh, 1995; Harvie, 2000; Zipperer and Skott, 2011; Blecker, 2016; Barrales and von Arnim, 2017; Charpe et al. 2019: Araujo et al., 2019) 13 In reality, then, the Goodwin pattern itself does not strictly conform to the behaviour of either a closed orbit or a limit cycle.

\section{Conclusions}

Once again, we are grateful to Emiliano Libman for both his generous praise of and critical remarks on our book. As Libman (2020, pp. 1-2) himself notes, any points of contention concern relatively minor issues that nevertheless merit further discussion - especially for the benefit of those readers interested in thinking through or progressing beyond some of the first approximations employed in $H M$. We hope that our contribution to this exchange serves this purpose.

\footnotetext{
${ }^{13}$ Charpe et al. (2019) find that the wage share leads growth positively at very low frequencies, which is inconsistent with the Goodwin pattern.
} 


\section{References}

Araujo, R. and G. Lima (2007). A structural economic dynamics approach to balance-ofpayments-constrained growth. Cambridge Journal of Economics 31(5), 755-774.

Araujo, R. A., M. J. Dávila-Fernández, and H. N. Moreira (2019). Some new insights on the empirics of Goodwin's growth-cycle model. Structural Change and Economic Dynamics 51, $42-54$.

Barbosa-Filho, N. and L. Taylor (2006). Distributive and demand cycles in the US economy: a structuralist Goodwin model. Metroeconomica 57(3), 389-411.

Barrales, J. and R. von Arnim (2017). Longer-run distributive cycles: wavelet decompositions for the US, 1948-2011. Review of Keynesian Economics 5(2), 196-217.

Blecker, R. (2016). Wage-led versus profit-led demand regimes: the long and the short of it. Review of Keynesian Economics 4(4), 373-390.

Blecker, R. and M. Setterfield (2019). Heterodox Macroeconomics: Models of Demand, Distribution and Growth. Cheltenham, UK: Edward Elgar.

Charpe, M., S. Bridji, and P. McAdam (2019). Labor share and growth in the long run. Working Paper Series 2251, European Central Bank.

Cornwall, J. (1977). Modern Capitalism: Its Growth and Transformation. White Plains: M.E. Sharpe.

David, P. A. (1985). Clio and the economics of QWERTY. American Economic Review $75(2), 332-337$.

David, P. A. (2000). Path dependence, its critics and the quest for 'historical economics'. In P. Garrouste and S. Ioannides (Eds.), Evolution and Path Dependence in Economic Ideas: Past and Present. Cheltenham, UK: Edward. Elgar.

Dutt, A. K. (1990). Growth, Distribution and Uneven Development. Cambridge: Cambridge University Press.

Flaschel, P. and G. Groh (1995). The classical growth cycle: Reformulation, simulation and some facts. Economic Notes 24, 293-326.

Flaschel, P., H. Krämer, S. Luchtenberg, C. Proaño, and M. Setterfield (2020). Capitalism, Inclusive Growth, and Social Protection: Inherent Contradiction or Achievable Vision? Cheltenham, UK: Edward Elgar.

Foley, D., T. Michl, and D. Tavani (2019). Growth and Distribution, Second Edition. Cambridge, Massachusetts and London, England: Harvard University Press. 
Goodwin, R. (1967). A growth cycle. In C. Feinstein (Ed.), Socialism, Capitalism and Economic Growth, pp. 54-58. Cambridge: Cambridge University Press.

Grasselli, M. R. and A. Maheshwari (2017). A comment on 'Testing Goodwin: growth cycles in ten OECD countries'. Cambridge Journal of Economics 41(6), 1761-1766.

Harcourt, G. C. (1972). Some Cambridge Controversies in the Theory of Capital. Cambridge, UK: Cambridge University Press.

Harris, D. J. (1978). Capital Accumulation and Income Distribution. Stanford, CA, USA: Stanford University Press.

Harvie, D. (2000). Testing Goodwin: growth cycles in ten OECD countries. Cambridge Journal of Economics $24(3), 349-376$.

Heilbroner, R. L. and W. S. Milberg (1996). The Crisis of Vision in Modern Economic Thought. Cambridge: Cambridge University Press.

Kiefer, D. and C. Rada (2015). Profit maximising goes global: the race to the bottom. Cambridge Journal of Economics 39(5), 1333-1350.

Kurz, H. D. and N. Salvadori (1995). Theory of Production: A Long-Period Analysis. Cambridge, UK: Cambridge University Press.

Libman, E. (2020). A note on Heterodox Macroeconomics by Blecker and Setterfield. European Journal of Economics and Economic Policies: Intervention.

Marglin, S. (1984). Growth, distribution and prices. Cambridge, MA: Harvard University Press.

Nikiforos, M. (2017). Uncertainty and contradiction: An essay on the business cycle. Review of Radical Political Economics 49(2), 247-264.

Pasinetti, L. L. (1977). Lectures on the Theory of Production. New York: Columbia University Press.

Pasinetti, L. L. (1981). Structural Change and Economic Growth: A Theoretical Essay on the Dynamics of the Wealth of Nations. Cambridge: Cambridge University Press.

Robinson, J. (1956). The Accumulation of Capital. London: Macmillan.

Robinson, J. (1975). The unimportance of reswitching. Quarterly Journal of Economics 89(1), 32-39.

Ros, J. (2013). Rethinking Economic Development, Growth, and Institutions. Oxford, UK: Oxford University Press.

Rosenberg, N. (1976). Perspectives on Technology. Cambridge: Cambridge University Press. 
Shaikh, A. (2012). The empirical linearity of Sraffa's critical output-capital ratios. In C. Gehrke, N. Salvadori, I. Steedman, and R. Sturn (Eds.), Classical Political Economy and Modern Theory: Essays in Honour of Heinz Kurz, pp. 89-101. London: Routledge.

Shaikh, A. (2016). Capitalism: Competition, Conflict, Crises. Oxford: Oxford University Press.

Skott, P. (1989). Conflict and effective demand in economic growth. Cambridge, UK: Cambridge University Press.

Solow, R. M. (1956). A contribution to the theory of economic growth. Quarterly Journal of Economic 70(1), 65-94.

Stockhammer, E. and J. Michell (2016). Pseudo-Goodwin cycles in a Minsky model. Cambridge Journal of Economics 41(1), 105-125.

Thirlwall, A. (2013). Economic Growth in an Open Developing Economy: The Role of Structure and Demand. Cheltenham, UK: Edward Elgar.

Zipperer, B. and P. Skott (2011). Cyclical patterns of employment, utilization, and profitability. Journal of Post Keynesian Economics 34 (1), 25-58. 